\title{
Perilaku Ibu Hamil Yang Mengalami Resiko Tinggi Di Puskesmas Kedungmundu Kota Semarang
}

\author{
Fransiska Irene Binsasi ; Lestari Puji Astuti ; Maftuchah \\ STIKES KARYA HUSADA SEMARANG
}

Email : fransiskaireneb@yahoo.co.id

\begin{abstract}
ABSTRAK
Latar Belakang: Angka kematian ibu yang mengalami resiko tinggi di Puskesmas Kedungmundu Semarang tahun 2016 bulan januari sampai juli sebanyak 3 orang dari jumlah 259 ibu hamil resiko tinggi. Faktor yang berpengaruh terhadap kehamilan resiko tinggi adalah sikap dan perilaku ibu sendiri selama hamil didukung oleh pengetahuan. Dengan adanya pengetahuan yang lebih tentang kehamilan resiko tinggi maka ibu akan menentukan sikap dan perilaku untuk mencegah dan mengatasi resiko kehamilan tinggi. Tujuan: Untuk mengetahui perilaku ibu hamil yang mengalami resiko tinggi. Metode : Kualitatif dengan pendekatan fenomenologi, data diambil dari 3 partisipan dan saturasi data dengan triangulasi sumber. Hasil : Hasil wawancara mendalam pada partisipan didapatkan informasi tentang perilaku respondent respon yaitu adanya respon yang relatif tetap karena mengikuti anjuran dari bidan. perilaku operant respon yaitu adanya rangsangan dari luar yang membantu ibu untuk melakukan pemeriksaan kehamilan serta menjaga kesehatan ibu dan janin. perilaku tertutup ibu yaitu ibu mengatakan resiko tinggi adalah ibu yang memiliki tekanan darah tinggi, terdapat bengkak pada wajah, tangan dan kaki, serta hamil di bawah usia 18 tahun dan usia di atas 35 tahun dan perilaku untuk mengatasi resiko tinggi dengan rajin memeriksakan kehamilan. perilaku terbuka ibu yaitu memeriksakan kehamilan sesuai jadwal serta memeriksakan diri ketenaga kesehatan, minum obat sesuai anjuran bidan saat sakit. Kesimpulan : Bagi ibu hamil resiko tinggi untuk selalu menjaga perilaku sehari-hari sehingga tidak berdampak buruk bagi kesehatan ibu dan janin.
\end{abstract}

Kata Kunci: Perilaku ibu hamil; resiko tinggi kehamilan

Daftar Pustaka : 6 (2003 - 2016)

\section{The Behavior Of Wowan Who Are Pregnant With High Of Risk In Public Health Center Of Kedungmundu Semarang City}

\begin{abstract}
Background: The number of woman past away who experinced of the high risk in Public Health Center of Kedungmundu Semarang in 2016 between January and July are 3 people from total 259 woman who have a high risk of pregnant. The factor which influences the high risk of pregnancy are the attitude and mother's behavior between pregnant which is supported by knowledge. With more knowledge about the high risk of pregnancy, so that the mother will determine the attitude and behavior to prevent and eceed the high risk of pregnancy. Purpose : knowing the behavior of the pregnant woman who have a high risk. Method: the Qualitative research with phenomenological approach, the data have taken from 3 participants and the data saturation with triangulation source. Result: The result of deep interview from participant is taken the information about the behavior of respondent there is respon which relatives constant because the respondent follow the suggestion from midwife. The behavior of operant respon there is stimulation from outside which helps the mother doing
\end{abstract}


check up the pregnancy and taking care of the mother's health and fetus. The close mother's behavior are the mother said the high risk is the mother who has a high blood pressure, there are swollen in face, arms and legs, and pregnant under age of 18 and over age 35 and the behavior to overcome the high of risk with to be continuous check up the pregnancy. The open behavior of mother are to check up the pregnancy compatible with the schedule and to check up her selves in paramedic, consumption the medicine correct to the suggestion of midwefery when they are sick. Suggestion: For the pregnant woman who have a high risk is always protecting the daily behavior, thus, it is not has a negative impact for mother"s health and fetus.

Key Words : The behavior of pregnant woman; the high risk of pragnancy

Literature : $6(2003-2006)$

\section{Pendahuluan / Latar Belakang}

Angka Kematian Ibu (AKI) merupakan salah satu indikator untuk melihat derajat kesehatan perempuan. Kematian maternal dan perinatal merupakan masalah besar, khususnya di Negara sedang berkembang sebanyak 98 - 99\% kematian maternal dan perinatal terjadi sedangkan di negara maju hanya $1-2 \%$. Tinggi rendahnya AKI di suatu wilayah dijadikan sebagai indikator yang menggambarkan besarnya masalah kesehatan, kualitas pelayanan kesehatan dan sumber daya di suatu wilayah ${ }^{(1)}$.

Kehamilan resiko tinggi adalah kehamilan atau janinnya mempunyai outcome yang buruk apabila dilakukan tata laksana secara umum seperti yang dilakukan pada kasus normal. Dengan demikian, untuk menghadapi kehamilan resiko harus diambil sikap proaktif, berencana dengan upaya promotif dan preventif sampai dengan waktunya harus diambil sikap tegas dan cepat untuk dapat menyelamatkan ibu dan bayinya ${ }^{(1)}$.

Angka kematian ibu yang mengalami resiko tinggi di Puskesmas KedungMundu pada 3 tahun terakhir di dapatkan data pada tahun 2014 adalah 1 orang karena ekalmpsia, pada tahun 2015 sebanyak 1 orang karena penyakit yang diderita ibu dan pada tahun 2016 Januari Juli sebanyak 3 orang dikarenakan penyakit yang diderita ibu dan keadaan social ekonomi rendah, dari data yang diperoleh menunjukan angka kematian ibu yang mengalami resiko tinggi di Puskesmas KedungMundu mengalami peningkatan. Di Puskesmas KedungMundu, jumlah ibu hamil yang mengalami resiko tinggi pada tahun 2016 bulan Januari - Juli sebanyak 259 orang. Studi pendahuluan pada bulan agustus 2016 di Puskesmas KedungMundu, pada saat dilaksanakan wawancara pada 5 orang ibu hamil ditemukan 3 orang ibu hamil resiko tinggi mengetahui tentang resiko tinggi dan perilaku 1 diantaranya masih mengonsumsi makanan yang manis dan asin serta memiliki tinggi badan $143 \mathrm{~cm}$, sedangkan 2 orang ibu hamil perilakunya yaitu tidak mengonsumsi makanan yang manis dan asin serta riwayat seksio sesaria dan memiliki penyakit Diabetes Melitus. sedangkan 2 orang ibu hamil lainnya yang bukan resiko tinggi belum mengetahui tentang resiko tinggi sehingga perilaku sehari- 
harinya masih jarang memeriksakan kehamilannya secara teratur, kurang menjaga kebersihan lingkungan serta jarang mengonsumsi makanan yang bergizi dimana perilaku seperti ini dapat menyebabkan ibu hamil tersebut bisa mengalami resiko tinggi ${ }^{(2)}$.

\section{Tinjauan Teoritis}

Skiner (1939) dalam (3) seorang ahli psikologi, merumuskan bahwa perilaku merupakan respon atau reaksi seseorang terhadap stimulus (rangsangan dari luar). Oleh karena perilaku ini terjadi melalui proses adanya stimulus terhadap organisme, dan kemudian organisme tersebut merespon, maka teori Skiner ini disebut teori "S-O-R" atau Stimulus Organisme Respon, dibedakan menjadi dua respon, yaitu:

1) Respondent respons atau revlexive, yakni respons yang ditimbulkan oleh rangsanganrangsangan (stimulus) tertentu. Stimulus semacam ini disebut eliciting stimulation karena menimbulkan respon- respon yang relatif tetap.

2) Operant respons atau instrumental respons, yakni respon yang timbul dan berkembang kemudian diikuti oleh stimulus atau perangsang tertentu. Perangsang ini disebut reinforcing stimulation atau reinforcer, karena memperkuat respons. Misalnya apabila seorang petugas kesehatan melakukan tugasnya dengan baik kemudian memperoleh penghargaan dari atasannya (stimulus baru), maka petugas kesehatan tersebut akan lebih baik dalam melaksanakan tugasnya.

Selanjutnya Skiner (1939) dalam ${ }^{(3)}$ membedakan bentuk respons terhadap stimulus ini menjadi: 1) Perilaku tertutup (cover behaviour) Respon seseorang terhadap stimulus dalam bentuk terselubung atau tertutup (covert). Respon atau reaksi terhadap stimulus ini masih terbatas, pada perhatian, persepsi, pengetahuan/kesadaran, dan sikap yang terjadi pada orang yang menerima stimulus tersebut, dan belum dapat diamati secara jelas oleh orang lain. Dalam hal ini orang lain belum bisa melihat atau mengobservasi secara nyata perilaku yang akan dilakukan, karena belum diaplikasikan dalam bentuk tindakan nyata, namun hanya orang yang menerima stimulus tersebut yang mengetahui apa yang akan dilakukan. Oleh sebab itu, disebut covert behaviour atau unobservable behaviour. 2) Perilaku terbuka (Over behaviour) Respon seseorang terhadap stimulus dalam bentuk tindakan nyata atau terbuka. Respon terhadap stimulus tersebut sudah jelas dalam bentuk tindakan atau praktik (practice), yang dengan mudah dapat diamati atau dapat dilihat oleh orang lain. Contoh yang dapat di jelaskan 
disini terkait dengan kehamilan adalah pemeriksaan Antenatal Care $(A N C)$, pilihan penolong persalinan, pilihan tempat persalinan, kepatuhan minum obat, kepatuhan dalam menjalankan pendidikan kesehatan yang diberikan tenaga kesehatan. Oleh sebab itu disebut over behaviour, tindakan nyata atau praktik (practice).

Berdasarkan batasan perilaku dari Skiner tersebut, maka perilaku kesehatan adalah suatu respons seseorang terhadap stimulus atau objek yang berkaitan dengan sakit dan penyakit, sistem pelayanan kesehatan, makanan, dan minum, serta lingkungan.

Kehamilan resiko tinggi adalah kehamilan yang menyebabkan terjadinya bahaya dan komplikasi yang lebih besar terhadap ibu maupun janin yang dikandungnya selama kehamilan, persalinan ataupun nifas bila dibandingkan dengan kehamilan, persalinan dan nifas normal.

\section{Metode Penelitian}

Pada penelitian ini, peneliti menggunakan pendekatan fenomenologi, karena pendekatan fenomenologi mencoba mencari arti pengalaman kehidupan. Dalam hal ini, peneliti mencoba memahami perilaku ibu hamil dengan resiko tinggi. Tempat penelitian di kelurahan tandang, waktu penelitian bulan Desember 2016 - Januari 2017, Subyek Penelitian dilakukan terhadap ibu hamil yang berada di wilayah kerja Puskesmas Kedungmundu, Cara Penetapan Partisipan pada penelitian ini, pemilihan partisipan secara acak tetapi dengan Purposive Sample yaitu teknik pengambilan sampel yang dilakukan dengan cara mengambil subjek bukan didasarkan atas adanya strata random atau daerah tetapi didasarkan adanya tujuan. Pengambilan sampel secara purposive didasarkan pada suatu pertimbangan tertentu yang dibuat oleh peneliti sendiri, berdasarkan ciri atau sifat-sifat populasi yang sudah diketahui sebelumnya ${ }^{(4)}$, alat yang digunakan pedoman wawancara, rekaman, camera, teknik pengumpulan data menggunakan wawancara mendalam (In Depth Interview). 


\section{Hasil dan Pembahasan}

1. Mengeksplorasi perilaku respondent respon ibu hamil yang mengalami resiko tinggi.

Berdasarkan hasil wawancara yang sudah dilakukan 2 orang partisipan sudah melakukan setiap anjuran yang diberikan bidan/dokter SpOG seperti: rajin memeriksakan kehamilan, rajin meminum tablet penambah darah dan vitamin yang diberikan bidan/dokter SpOG, sedangkan 1 partisipan melakukan anjuran yang di berikan dokter juga seperti memeriksakan kehamilannya, namun partisipan ini tidak mengkonsumsi tablet penambah darah di karenakan sering mual muntah dan apabila mengkonsumsi tablet penambah darah langsung dimuntahkan kembali.

Perilaku (manusia) adalah semua kegiatan atau aktivitas manusia, baik yang dapat diamati langsung, maupun yang tidak dapat diamati oleh pihak luar. Sesuai dengan teori Skiner (1939) dalam ${ }^{(3)}$ seorang ahli psikologi, merumuskan bahwa perilaku merupakan respon atau reaksi seseorang terhadap stimulus (rangsangan dari luar).

Oleh karena perilaku ini terjadi melalui proses adanya stimulus terhadap organisme, dan kemudian organisme tersebut merespon. Respondent respons atau revlexive, yakni respons yang ditimbulkan oleh rangsangan-rangsangan (stimulus) tertentu. Stimulus semacam ini disebut eliciting stimulation karena menimbulkan respon- respon yang relatif tetap.

Berdasarkan hasil penelitian dan teori yang ada menunjukan bahwa respon dari ke 2 ibu hamil ini relatif tetap karena mengikuti anjuran dari bidan dan dokter SpOG, di mana selalu memeriksakan kehamilan dan meminum tablet penambah darah atau vitamin yang diberikan. Respon yang relatif tetap yang dilakukan oleh kedua ibu hamil ini merupakan hasil yang baik dimana respon seperti inilah yang diharapkan agar ibu hamil lainnya juga melakukan atau memiliki respon yang sama agar selama masa kehamilannya tetap menjaga kesehatan dari janin dan ibunya sendiri, sedangkan 1 partisipan melakukan anjuran yang di berikan dokter juga seperti memeriksakan kehamilannya, namun partisipan ini tidak mengkonsumsi tablet penambah darah di karenakan sering mual muntah dan apabila mengkonsumsi tablet penambah darah langsung dimuntahkan kembali. Seharusnya partisipan mengkonsumsi tablet penambah darah karena partisipan mengalami anemia

Pada penelitian ini didukung dengan penelitian dari ${ }^{(5)}$ yang menyebutkan perilaku dari ibu hamil resiko tinggi yaitu mengikuti saran dan anjuran dari dokter, dimana dibutuhkan perilaku yang baik selain mengikuti saran dan anjuran dari bidan/dokter namun juga rajin 
memeriksakan kehamilannya agar mencegah atau bisa mengantisipasi dampak yang lebih parah yang dapat terjadi pada ibu dan janin.

2. Mengeksplorasi perilaku operant respon ibu hamil yang mengalami resiko tinggi

Berdasarkan hasil wawancara partisipan 1, 2 dan 3 menyatakan bahwa melakukan pemeriksaan untuk mengetahui perkembangan kesehatan janin serta perlu menjaga kesehatan agar saat melahirkan ibu dan janin juga tetap sehat. Skiner (1939) dalam ${ }^{(3)}$ seorang ahli psikologi, merumuskan bahwa perilaku merupakan respon atau reaksi seseorang terhadap stimulus (rangsangan dari luar), Operant respons atau instrumental respons, yakni respon yang timbul dan berkembang kemudian diikuti oleh stimulus atau perangsang tertentu. Perangsang ini disebut reinforcing stimulation atau reinforcer, karena memperkuat respons. Pada saat melakukan pemeriksaan kehamilan bidan memberi KIE (Komunikasi Informasi Edukasi) kepada ibu hamil, suami dan keluarganya tentang kondisi ibu hamil dan masalahnya. Perawatan yang diberikan kepada ibu hamil secara berkala dan teratur selama masa kehamilan sangat penting, sebab merupakan upaya bersama antara petugas kesehatan dan ibu hamil, suami, keluarga dan masyarakat, mengenai: aspek kesehatan dari ibu dan janin untuk menjaga kelangsungan kehamilan, pertumbuhan janin dalam kandungan kelangsungan hidup ibu dan bayi setelah lahir. Berdasarkan hasil penelitian dan teori yang ada menunjukan bahwa adanya dorongan atau rangsangan dari luar membantu ibu untuk melakukan pemeriksaan kehamilan dan menjaga kesehatan ibu dan janin serta menjaga kelangsungan kehamilan, pertumbuhan janin dalam kandungan serta kelangsungan hidup ibu dan bayi yang dilahirkan. Pada penelitian ini didukung dengan penelitian dari ${ }^{(5)}$ yang menyebutkan perilaku dari ibu hamil resiko tinggi yaitu mencari informasi tentang kehamilannya dan menanyakan kondisi kehamilannya kepada tenaga kesehatan.

\section{Mengeksplorasi perilaku tertutup ibu hamil yang mengalami resiko tinggi}

Berdasarkan hasil wawancara partisipan 1, 2 dan 3 menyatakan bahwa resiko tinggi, yaitu: ibu yang memiliki tekanan darah tinggi, terdapat bengkak pada wajah, tangan dan kaki atau biasa hamil usia muda dibawah 18 dan 20 tahun serta hamil usia tua diatas 35 tahun, anemia dan perilaku untuk mengatasi resiko tinggi yaitu rajin memeriksakan kehamilannya dan mengikuti anjuran yang diberikan bidan. ${ }^{(6)}$ mengemukakan kriteria kehamilan resiko tinggi adalah primimuda, primitua, umur 35 tahun atau lebih, tinggi badan kurang dari $145 \mathrm{~cm}$, grandemulti, riwayat persalinan yang buruk, bekas seksio sesaria, pre-eklampsia, hamil serotinus, perdarahan antepartum, kelainan letak, Bengkak pada muka / tungkai dan tekanan darah tinggi kelainan medis dan lain-lain. Perilaku tertutup (cover behaviour) yaitu Respon seseorang terhadap stimulus dalam bentuk terselubung atau tertutup (covert). Respon atau 
reaksi terhadap stimulus ini masih terbatas, pada perhatian, persepsi, pengetahuan/kesadaran, dan sikap yang terjadi pada orang yang menerima stimulus tersebut dan belum dapat diamati secara jelas oleh orang lain. Berdasarkan hasil penelitian dan teori yang ada menunjukan bahwa perilaku ibu belum dapat di amati oleh orang lain karena belum diaplikasikan dalam bentuk tindakan nyata, perilaku ibu masih terbatas pada persepsi dan pengetahuan tentang kehamilan resiko tinggi dan perilaku untuk mengatasi resiko tinggi yang belum dapat diamati orang lain. Pada penelitian ini didukung dengan penelitian dari (7) yang menyebutkan pengetahuan dari semua ibu hamil dapat memberikan jawaban bahwa resiko tinggi tersebut berbahaya bagi ibu maupun janin. Ibu hamil mengetahui bahwa usia juga bisa menyebabkan resiko tinggi kehamilan, tidak hanya itu saja ibu hamil tahu bahwa ibu dengan tinggi badan yang pendek juga bisa menyebabkan terjadinya resiko tinggi kehamilan, penyakit gula dan asma juga bisa menyebabkan terjadinya resiko tingi kehamilan.

4. Mengeksplorasi perilaku terbuka ibu hamil yang mengalami resiko tinggi

Berdasarkan hasil wawancara partisipan 1 dan 3 menyatakan bahwa memeriksakan kehamilan sesuai jadwal sedangkan partisipan 2 memeriksakan kehamilan tidak sesuai jadwal dan hasil wawancara partisipan 1,2,3 tentang perilaku dalam menjaga kesehatan agar tidak sakit atau upaya untuk menyembuhkan sakit yaitu memeriksakan diri ke tenaga kesehatan minum obat sesuai anjuran bidan/dokter. Perilaku terbuka (Over behaviour) yaitu respon seseorang terhadap stimulus dalam bentuk tindakan nyata atau terbuka. Respon terhadap stimulus tersebut sudah jelas dalam bentuk tindakan atau praktik (practice), yang dengan mudah dapat diamati atau dapat dilihat oleh orang lain. Contoh yang dapat di jelaskan disini terkait dengan kehamilan adalah pemeriksaan Antenatal Care $(A N C)$, pilihan penolong persalinan, pilihan tempat persalinan, kepatuhan minum obat, kepatuhan dalam menjalankan pendidikan kesehatan yang diberikan tenaga kesehatan. Oleh sebab itu disebut over behaviour, tindakan nyata atau praktik (practice). Perilaku kesehatan adalah suatu respons seseorang terhadap stimulus atau objek yang berkaitan dengan sakit dan penyakit, sistem pelayanan kesehatan, makanan, dan minum, serta lingkungan. Berdasarkan hasil penelitian dan teori yang ada menunjukan bahwa perilaku ibu dapat di amati oleh orang lain karena sudah diaplikasikan dalam bentuk tindakan nyata dimana memeriksakan kehamilan sesuai jadwal dan memeriksakan diri ke tenaga kesehatan, minum obat sesuai anjuran bidan/dokter saat sakit. Pada penelitian ini didukung dengan penelitian dari ${ }^{(5)}$ tentang perilaku ibu hami resiko tinggi yang juga melakukan kontrol di Rumah Sakit secara teratur dan mengikuti saran dan anjuran yang diberikan dokter. 


\section{Kesimpulan}

1. Perilaku Respondent Respon ibu hamil yang mengalami resiko tinggi Partisipan 1 dan 3 menyatakan bahwa bentuk perilaku respondent respon ibu hamil yang mengalami resiko tinggi yaitu melakukan anjuran dari bidan atau dokter SpOG seperti periksa kehamilan dan mengonsumsi tablet penambah darah dan vitamin, sedangkan partisipan 2 sering memeriksakan kehamilannya tapi tidak tepat waktu dan tidak mengkonsumsi tablet penambah darah.

2. Perilaku Operant respon ibu hamil yang mengalami resiko tinggi

a. Pemeriksaan Kehamilan, semua partisipan 1,2 dan 3 menyatakan bahwa bentuk perilaku operant respon ibu hamil yang mengalami resiko tinggi yang membuat partisipan untuk melakukan pemeriksaan kehamilan yaitu untuk mengetahui perkembangan dan kesehatan janin

b. Menjaga kesehatan ibu dan Janin, semua partisipan 1,2 dan 3 menyatakan bahwa bentuk perilaku operant respon ibu hamil yang mengalami resiko tinggi yang membuat partisipan untuk tetap menjaga kesehatan ibu dan janin yaitu agar saat melahirkan ibu dan janin juga tetap sehat.

3. Perilaku tertutup ibu hamil yang mengalami resiko tinggi

a. Kehamilan Resiko tinggi, semua partisipan 1,2 dan 3 menyatakan bahwa bentuk perilaku tertutup ibu hamil yang mengalami resiko tinggi dalam hal ini yang partisipan ketahui tentang kehamilan resiko tinggi yaitu ibu yang memiliki tekanan darah tinggi, terdapat bengkak pada wajah, tangan dan kaki atau biasa hamil usia muda dibawah 18 dan 20 tahun serta hamil usia tua diatas 35 tahun.

b. Perilaku untuk mengatasi resiko tinggi, semua partisipan 1,2 dan 3 menyatakan bahwa bentuk perilaku tertutup ibu hamil yang mengalami resiko tinggi dalam mengatasi resiko tinggi yaitu rajin memeriksakan kehamilannya dan mengikuti anjuran yang diberikan bidan.

4. Perilaku terbuka ibu hamil yang mengalami resiko tinggi

a. Memeriksakan kehamilan sesuai jadwal, partisipan 1 dan 3 menyatakan bahwa bentuk perilaku terbuka ibu hamil yang mengalami resiko tinggi yaitu periksa kehamilan sesuai jadwal sedangkan partisipan 2 menyatakan bahwa bentuk perilaku terbuka ibu hamil yang mengalami resiko tinggi yaitu periksa kehamilan sesuai waktu luang dan libur suami.

b. Perilaku dalam menjaga kesehatan agar tidak sakit atau upaya untuk menyembuhkan sakit, semua Partisipan 1,2 dan 3 menyatakan bahwa bentuk perilaku terbuka ibu hamil yang 
mengalami resiko tinggi dalam menjaga kesehatan agar tidak sakit atau upaya untuk menyembuhkan sakit yaitu memeriksakan diri ke tenaga kesehatan minum obat sesuai anjuran bidan/dokter .

\section{Saran}

Hasil penelitian ini diharapkan bisa menjadi masukan bagi ibu hamil resiko tinggi agar selalu menjaga perilaku sehari-hari, rajin memeriksakan kehamilannya sesuai jadwal, mengonsumsi tablet penambah darah, dan vitamin yang di berikan serta selalu mengikuti anjuran dari tenaga kesehatan sehingga tidak berdampak buruk bagi kesehatan ibu dan janin, Bagi Puskesmas KedungMundu Sebagai bahan masukan bagi tenaga kesehatan untuk mengevaluasi peningkatan kadar hemogoblin pada ibu dengan faktor anemia secara rutin,

\section{Referensi}

[1] Manuaba I.B.G , Chandranita Manuaba, Fajar Manuaba. 2007. Pengantar Kuliah Obstetri. Jakarta : EGC.

[2] Anymous. Buku Besar Puskesmas KedungMundu. 2016

[3] Notoadmojo, Soekidjo. 2007. Promosi Kesehatan dan Ilmu Perilaku. Jakarta : Rineka Cipta

[4] Arikunto, S. (2010). Prosedur Penelitian Suatu Pendekatan Praktek. Edisi Revisi. Jakarta : Rineka Cipta

[5] Hasugian, Tigor P. Tesis Magister, 2012. Pengetahuan, Sikap dan Perilaku Ibu Hamil Terhadap Kehamilan Resiko Tinggi di Rsup H. Adam Malik. Medan : Departemen Obstetri dan Ginekologi Fakultas Kedokteran Universitas Sumatera Utara.

[6] Rochjati, Poedji. 2003. Skrining Antenatal Pada Ibu Hamil. Surabaya: Universitas Erlangga

[7] Joan christiyanti, dkk.2015. Persepsi Ibu Hamil Dengan Faktor Resiko usia>35 Tahun Terhadap Resiko Tinggi Kehamilan, di Puskesmas Tlogosari Kulon pedurungan,Semarang.Semarang 